\title{
BIOETHANOL PRODUCTION THROUGH SYNGAS FERMENTATION BY A NOVEL IMMOBILIZED BIOREACTOR USING CLOSTRIDIUM RAGSDALEI
}

\author{
Simge SERTKAYA \\ Ege University, Research and Application Center for Environmental Problems
}

ORCID ID:

\section{Tugba KESKIN GUNDOGDU}

Izmir Democracy University, Department of Environmental Protection

ORCID ID:

\section{Christian KENNES}

University of A Coruña, Faculty of Sciences and Centre for Advanced Scientific Research

ORCID ID:

\section{Nuri AZBAR}

Ege University, Department of Bioengineering

ORCID ID:

\begin{abstract}
Global energy demand has been escalating creating ever increasing pressure on climate crisis caused by fossilbased fuels. Humankind is now desperately in need of alternative and sustainable energy sources. Therefore, biofuels provide promising solution.

Amongst the various biofuels, bioethanol from syngas, which is a mixture of, mostly, $\mathrm{CO}, \mathrm{CO}_{2}, \mathrm{~N}_{2}, \mathrm{H}_{2}$, and $\mathrm{CH}_{4}$ gases has been drawing increasing attention recently. Regarding this, the conversion of syngas to bioethanol, an alternative biofuel to fossil fuels, is considered a promising approach to reduce the negative effects of global warming by reducing greenhouse gas emissions.

In this study, a novel immobilized cell bioreactor, where Clostridium ragsdalei was grown, was designed and used to achieve an efficient production of ethanol regarding volumetric production. For this purpose, a $300 \mathrm{~mL}$ immobilized reactor filled with ceramic balls as immobilization material was set and operated at $30^{\circ} \mathrm{C}$ throughout the study where $\mathrm{CO}$ gas as the main substrate was fed at rate of $6 \mathrm{ml} / \mathrm{min}$ continuously. Results showed ethanol and acetic acid concentrations reaching up to $1.4 \mathrm{~g} / \mathrm{L}$ and $0.2 \mathrm{~g} / \mathrm{L}$, respectively, after $600 \mathrm{~h}$ with a volumetric production rate of $0,0023 \mathrm{~g}$ ethanol/L/h. We believe, the ceramic ball was used for bioethanol production for syngas for the first time.
\end{abstract}

Keywords: Air Pollution, Energy, Carbon Monoxide, Clostridium, Ethanol

\section{INTRODUCTION}

Air pollution is almost ranked as first cause that is threating and affecting the quality of life and human health. As a result of huge increase in human population and industrialization all over the world, the energy demand in the world has increased greatly. In parallel, the air pollution from fossil-based fuel consumption have caused significant increases in asthma and respiratory diseases. In addition, the increase in the concentration of greenhouse gases causes adverse effects such as severe floods and droughts, rising sea levels and extreme weather conditions. This energy demand is primarily tried to be overcome by using oil reserves, which are on the verge of exhaustion, but it is thought that these resources will be depleted in the next 50 years (DürreP and EikmannsBJ, 2015).

Amongst the various clean energy sources, bioethanol is one of the most promising alternative. Ethanol is one of the easiest to be used among alternative biofuels. Fuel ethanol is an oxygenated, water-free, high-octane (108) alcohol and is also known as a potential alternative fuel to gasoline (AdvancedBiofuelsUSA.org, 2011).

Bioethanol Production has many advantages such as being a renewable and clean fuel source, reducing dependency on fossil fuels, increasing the octane number of fuel at low cost, and being easily produced in every geography with synthesis gas fermentation. One of the biggest advantages is that it can be used by adding to gasoline. It is

Received I5 Augustl 2021; Received in revised farm 26 August 2021; Accepted 20 September 202I;

Available online 25 September 2021;

dai: I0.46291//CDNTECHval5iss3pp|3-20 
the most important fuel that can be an alternative to Methyl Tertiary Butyl Ether, which is used as oxygenate to increase the octane value of fuels. Today, it can be used by mixing at 10, 15, $20 \%$ (E10, E15, E20) ratios. The E85 is its pure form. The most important and beneficial property of ethanol is that it is a biodegradable chemical. It is ensured that harmful gas emissions such as $\mathrm{CO}, \mathrm{CO}_{2}$, VOCs and $\mathrm{NOx}$ are reduced by 5-10\%. In addition, ethanol is biodegradable and contains $35 \%$ oxygen, which reduces particulate and NOx emissions during combustion compared to conventional fuels.

Ethanol is produced biologically (bioethanol) from first generation sources (sugar beet, maize, glucose) directly by fermentation, from second generation sources (lignocellulosic wastes such as urban solid waste, grass, field waste) after the sugars are released by chemical and pre-treatment. Bioethanol production from biomass is still a costly and open to research process (PhillipsJR et al., 2017). Syngas is a mixture of gases whose content is mostly $\mathrm{CO}, \mathrm{CO}_{2}, \mathrm{~N}_{2}, \mathrm{H}_{2}$ and $\mathrm{CH}_{4}$. It is known as a toxic gas because of its $\mathrm{CO}$ content. Species such as Clostridium ljungdahlii, Clostiridium ragsdalei, Clsotiridium autoethanogenum can produce ethanol and acetic acid (acetate) from CO by Wood-Ljungdahl pathway under anaerobic conditions. Gas fermentation is among the most important topics that can be used for sustainable industrial fuel and chemical production.

Synthesis gas fermentation has prominent advantages such as the fact that the gas composition to be given to the reactor is not important, microorganisms can easily tolerate gaseous contaminants. Fermentation can take place at reasonable temperature and pressure, and the end products of fermentation are nontoxic products (AbubackarHN et al., 2012). Gas fermentation is a technology used to convert industrial waste gases, coal, biomass or municipal waste into fuel and chemicals. Synthesis gas fermentation results in the production of ethanol and acetic acid by a series of biochemical reactions known as the Wood-Ljungdahl pathway under anaerobic conditions. In the WoodLjungdahl pathway, the anaerobic conversion of CO to ethanol has been described in detail (KöpkeM et al., 2011).

The use of the following equations for the use of $\mathrm{CO}$ and $\mathrm{CO}_{2}+\mathrm{H}_{2}$ for ethanol and acetate production during autotrophic growth has been reported in the literature (CotterJL et al.,2009).

$$
\begin{aligned}
& 6 \mathrm{CO}+3 \mathrm{H}_{2} \mathrm{O} \rightarrow \mathrm{C}_{2} \mathrm{H}_{5} \mathrm{OH}+4 \mathrm{CO}_{2} \\
& 2 \mathrm{CO}_{2}+6 \mathrm{H}_{2} \rightarrow \mathrm{C}_{2} \mathrm{H}_{5} \mathrm{OH}+3 \mathrm{H}_{2} \mathrm{O} \\
& 4 \mathrm{CO}+2 \mathrm{H}_{2} \mathrm{O} \rightarrow \mathrm{CH}_{3} \mathrm{COOH}+2 \mathrm{CO}_{2} \\
& 2 \mathrm{CO}_{2}+4 \mathrm{H}_{2} \rightarrow \mathrm{CH}_{3} \mathrm{COOH}+2 \mathrm{H}_{2} \mathrm{O}
\end{aligned}
$$

According to the literature, ethanol production values of $0.48 \mathrm{~g} / \mathrm{L}$ (Fernández-NaveiraA et al., 2016) and 0.45 g/L (Ramió-PujolS et al., 2015) with Clostiridium carboxydivarans, $0.15 \mathrm{~g} / \mathrm{L}$ (Ramió-PujolS vd., 2015) and 0.337 g/L with Clostridium ljugdahlii and values changing between $0.17-1.33 \mathrm{~g} / \mathrm{L}$ with Clostridium ragsdalei (AcharyaB et al., 2019).

Although there are many studies on basal environment optimization with Clostridium ragsdalei in the literature, the number of reactor studies in the production of ethanol from syngas with Clostridium ragsdalei is few. The most commonly used reactor type is stirred tank reactors, and there are also limited number of studies conducted with trickle bed reactors. Devarapalli et al. (2017) reported $0.158 \mathrm{~g} / \mathrm{L}$ ethanol production per hour using trickle bed reactor (TBR; working volume of $1 \mathrm{~L}$ ) using Clostridium ragsdalei and syngas composed of \%38 CO, \%28,5 $\mathrm{CO}_{2}, \% 28,5 \mathrm{H}_{2}, \% 5 \mathrm{~N}_{2}$ using. Similarly, DevarapalliM et al., (2016) achieved maximum $5.7 \mathrm{~g} / \mathrm{L}$ ethanol production by using Clostridium ragsdalei in a $0.5 \mathrm{~L}$ TBR reactor.

Bioreactor systems using immobilized cell cultures have gained great interest in recent years, since gas fermentation processes requires high mass transfer capacities that meet the kinetic requirements of the microorganisms used. OrgillJJ et al., (2013) comparatively studied the volumetric mass transfer coefficients of the three reactor types namely, trickling reactor (TBR), hollow fiber membrane reactor (HFR) and stirred tank reactor (STR) for the fermentation of poorly soluble gases such as $\mathrm{CO}$ and $\mathrm{H}_{2}$ in order to produce biofuels and bio-based chemicals. The analysis was carried out using $\mathrm{O}_{2}$ as the gaseous mass transfer agent. The highest volumetric mass transfer coefficient was provided by HFR $\left(1062 \mathrm{~h}^{-1}\right)$, followed by TBR $\left(421 \mathrm{~h}^{-1}\right)$ with $6 \mathrm{~mm}$ beads, followed by STR $\left(114 \mathrm{~h}^{-1}\right)$. The mass transfer properties in each reactor were affected by the agitation rate and the gas and liquid flow rates. KundiyanaDK et al., (2011), reported $2 \mathrm{~g} / \mathrm{L}$ ethanol production by feeding gas with synthesis gas content of $40 \% \mathrm{CO}, 30 \% \mathrm{CO}_{2}, 30 \% \mathrm{H}_{2}$ to the reactors using Clostridium ragsdale $i$ in a two-stage CSTR reactor in $3 \mathrm{~L}$ fermenters with a maximum working volume of $2 \mathrm{~L}$. KundiyanaDK et al., (2010) used a fully mixed fermenter with a volume of $100 \mathrm{~L}$ operated in a semi-continuous mode. The reactor using Clostridium strain P11 was fed with a synthesis gas content of $20 \% \mathrm{CO}, 15 \% \mathrm{CO}_{2}, 5 \% \mathrm{H}_{2}, 60 \% \mathrm{~N}_{2}$, and $26.25 \mathrm{~g} / \mathrm{L}$ ethanol was produced per day. In this study, it was stated that the difficulty of large-scale inoculum production is one of the critical factors in large-scale fermentations. It is thought that this problem will be significantly minimized in pilot-scale high-volume studies, as it can be operated at high biomass concentrations in small volumes in immobilized bioreactors.

Received I5 Augustl 2021; Received in revised form 26 August 2021; Accepted 20 September 2021;

Available online 25 September 2021;

dai: 10.46291//CDNTECHval5iss3pp|3-20 
Immobilized bioreactors have advantages such as providing a special stability of the microorganism against environmental stresses, preventing cell wash-out even at high dilution rates in continuous operation mode, being able to recover immobilized cells from the solution without difficulty, and simplifying subsequent processes (ZhuY, 2007).

In this study, it is aimed to investigate immobilization of Clostridium ragsdalei as an important bacterial species on the ceramic ball materials for bioethanol production from syngas under continuous feeding condition. To the best of our knowledge, this is the first study in which ceramic ball was used for this purpose.

\section{MATERIALS AND METHODS}

\subsection{MICROORGANISMS AND GROWTH MEDIUM}

Clostridium ragsdalei (ATCC-BAA-622) was obtained from the ATCC (American Type Culture Collection). Anaerobic medium recommended by ATCC was used for revitalization. Microorganisms were maintained in a $20 \%$ glycerol stock at $-80^{\circ} \mathrm{C}$ for long-term preservation and persistence. The culture was activated after the revitalization process of the lyophilized microorganism inoculated into the reactor bottles in 1754 PETC nutrient medium before each new experiment in order to perform the reactivation process, and after this process, the fresh innoculum cultures were used for the experiments. Operations were carried out under sterile conditions next to the bunsen flame. Glass reactors with a volume of $100 \mathrm{ml}$ were used with $50 \mathrm{ml}$ working volume. After $10 \%$ inoculation, $5 \mathrm{ml}$ of inoculum was added to the reactor medium. It was kept in the air-conditioning room at $30^{\circ} \mathrm{C}$ for 1-2 days.

The growth medium (ATCC) contains the following elements per liter distilled water: $\mathrm{NH}_{4} \mathrm{Cl}(1 \mathrm{~g}), \mathrm{KCl}(0.1 \mathrm{~g})$, $\mathrm{MgSO}_{4} \times 7 \mathrm{H}_{2} \mathrm{O}(0.2 \mathrm{~g}), \mathrm{NaCl}(0.8 \mathrm{~g}), \mathrm{KH}_{2} \mathrm{PO}_{4}(0.1 \mathrm{~g}), \mathrm{CaCl}_{2} \times 2 \mathrm{H}_{2} \mathrm{O}(0.02 \mathrm{~g})$, Yeast extract $(1 \mathrm{~g}, \mathrm{Merck}), 10 \mathrm{ml}$ trace element solution, Wolfe's vitamin solution $(10 \mathrm{ml}), \mathrm{NaHCO}_{3}(2 \mathrm{~g})$, Fructose $(5 \mathrm{~g})$, reducing agent $10 \mathrm{ml}$. Trace element stock solution per liter distilled water includes: $2 \mathrm{~g}$ nitrilotriacetic acid, $1 \mathrm{~g} \mathrm{MnSO}_{4} \times \mathrm{H}_{2} \mathrm{O}, 0.8 \mathrm{~g}$ $\mathrm{Fe}\left(\mathrm{SO}_{4}\right)_{2}\left(\mathrm{NH}_{4}\right)_{2} \times 6 \mathrm{H}_{2} \mathrm{O}, 0.2 \mathrm{~g} \mathrm{CoCl}_{2} \times 6 \mathrm{H}_{2} \mathrm{O}, 0.2 \mathrm{~g} \mathrm{ZnSO}_{4} \times 7 \mathrm{H}_{2} \mathrm{O}, 0.02 \mathrm{~g} \mathrm{CuCl}_{2} \times 2 \mathrm{H}_{2} \mathrm{O}, 0.02 \mathrm{~g} \mathrm{NiCl}_{2} \times 6 \mathrm{H}_{2} 0$, $0.02 \mathrm{~g} \mathrm{Na}_{2} \mathrm{MoO}_{4} \times 2 \mathrm{H}_{2} \mathrm{O}, 0.02 \mathrm{~g} \mathrm{Na}_{2} \mathrm{SeO}_{4}, 0.02 \mathrm{~g} \mathrm{Na}_{2} \mathrm{WO}_{4}$. Vitamin stock solution per liter distilled water contains: $2 \mathrm{mg}$ biotin, $2 \mathrm{mg}$ folic acid, $10 \mathrm{mg}$ pyridoxine hydrochloride, $5 \mathrm{mg}$ thiamine hydrochloride, $5 \mathrm{mg}$ riboflavin, 5 $\mathrm{mg}$ nicotinic acid, $5 \mathrm{mg}$ Calcium D-(+)-pantothenate, $0.1 \mathrm{mg}$ Vitamin B12, $5 \mathrm{mg}$ p-aminobenzoic acid, $5 \mathrm{mg}$ thioctic acid. Reducing agent stock solution per liter distilled water contains: 0,9 g NaOH, $4 \mathrm{~g}$ L-Cysteine hydrochloride, $4 \mathrm{~g} \mathrm{Na}_{2} \mathrm{~S} \times 9 \mathrm{H}_{2} \mathrm{O}$.

The inoculum solution to be used in the experimental system was prepared by inoculation of $10 \%$ into the fructose containing growth medium for stable growth of the strain.

\subsection{IMMOBILIZED BIOREACTORS EXPERIMENTAL SETUP AND PROCESS}

In this study, it is aimed to achieve high volumetric production in small volume bioreactors. For this reason, an immobilized bioreactor design was used. The schematic description of the reactor is shown in Figure 1. The reactor is an upstream $300 \mathrm{ml}$ immobilized anaerobic reactor (diameter of $4,5 \mathrm{~cm}$ and a height of $30 \mathrm{~cm}$ ) filled with ceramic balls (EHEIM substrate biofilter medium; $450 \mathrm{~m}^{2} / \mathrm{l}$ ) as immobilization material. Fermentation was carried out using Clostridium ragsdalei strain, which is capable of ethanol production from continuously fed CO by WoodLjungdahl pathway under anaerobic conditions. Bioreactor working volume and operating temperature were 150 $\mathrm{ml}$ and at $30^{\circ} \mathrm{C}$, respectively. 


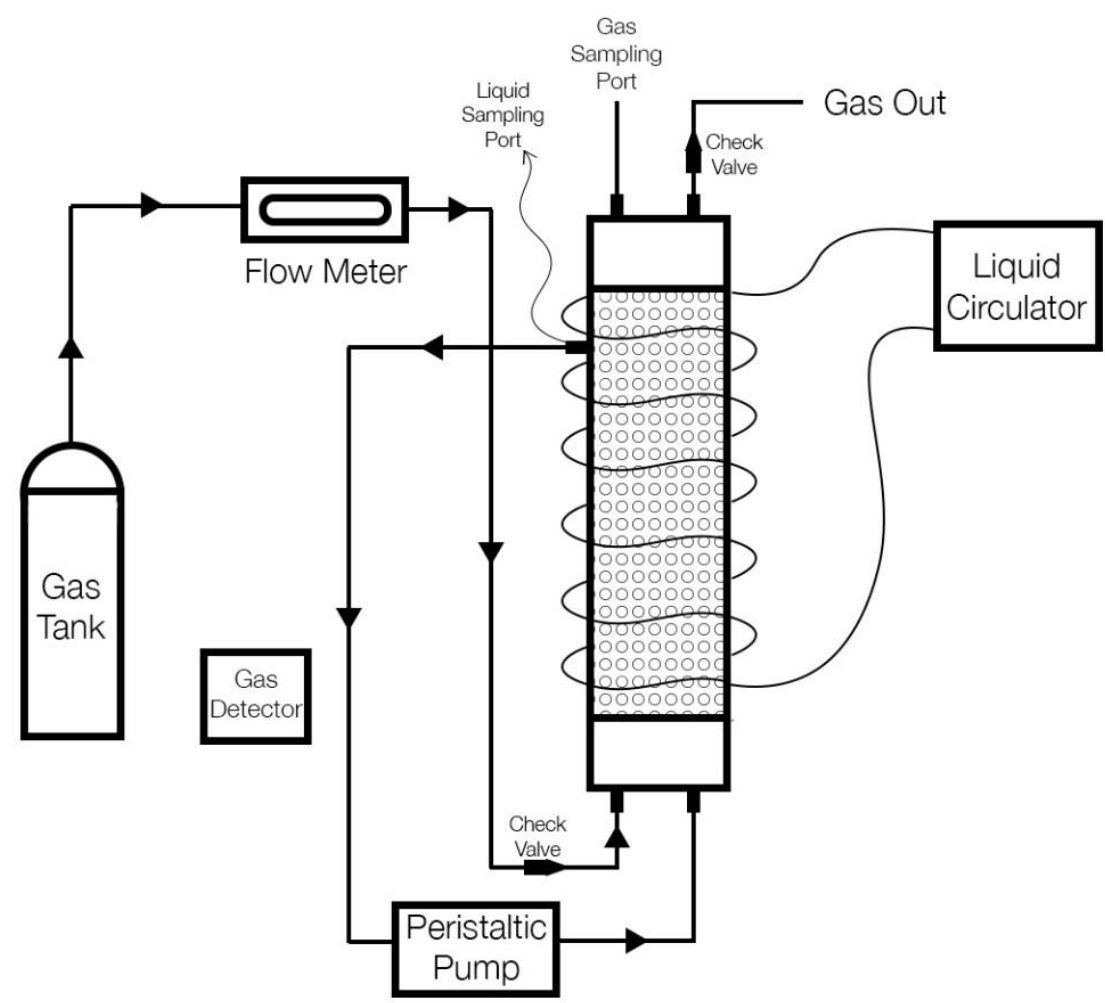

Figure 1. Continuous Feed Immobilized Reactor Setup

The reactor was first filled with ceramic balls and sterilized in an autoclave (Raypa, Barcelona-Spain) at $121^{\circ} \mathrm{C}$ for 20 minutes. Before and immediately after the inoculum addition, anaerobic medium was purged with $99 \%$ pure nitrogen to remove oxygen in the reactor for at least $2 \mathrm{~h}$. The inoculum solution was fed from bottom to top with a peristaltic pump, and samples were taken from the influent and effluent. The cycle was continued for 48 hours without interruption. The reactor is wrapped with silicon tubes connected to a heat circulator to keep the temperature at $30^{\circ} \mathrm{C}$. The liquid recirculation rate was set at $40 \mathrm{~mL} / \mathrm{min}$. After the fructose amount in the reactor was depleted, bioethanol and acetic acid production performances were investigated by feeding $6 \mathrm{ml} / \mathrm{min}$ pure CO gas to the reactors from bottom to top with the help of a mass flow controller (Aalborg GFC 17, Müllheim, Germany).

\subsection{ANALYTICAL METHODS}

The growth of microorganism was monitored at $600 \mathrm{~nm}$ using a spectrophotometer (PERKIN ELMER UV/VIS, United States of America) against a blank of pure water. Medium $\mathrm{pH}$ values and daily $\mathrm{pH}$ changes were monitored with a pH Meter (CRISON, Spain). The concentrations of metabolites (ethanol and acetic acid) were determined using High Performance Liquid Chromatography (HPLC) (HP1100, Agilent Co., United States of America) with a Refractive Index Detector (RID). The column was a Agilent Hi-Plex H (300 x $7.7 \mathrm{~mm})$. The carrier liquid was $0.005 \mathrm{M} \mathrm{H}_{2} \mathrm{SO}_{4}$ at a flow rate of $0,80 \mathrm{ml} / \mathrm{min}$, at a pressure of $7 \mathrm{bar}$, and at a column temper-ature of $45^{\circ} \mathrm{C}$ and Refractive Index Detector temperature of $45^{\circ} \mathrm{C}$. Prior to analysis, the samples were centrifuged (ELMI Skyline Ltd CM $70 \mathrm{M} 07$ ) at $7000 \mathrm{rpm}$ for 10 minutes and the supernatant filtered through $0.22 \mu \mathrm{m}$ filters (Labbox, Barcelona, Spain). The Pure CO Cylinder has a volume of $10 \mathrm{~L}$ and has a special regulator for chrome CO. The purity of the culture was confirmed via 16S rDNA gene sequencing (Fernández-Naveira et al., 2017).

\section{RESULTS AND DISCUSSION}

\subsection{S RDNA GENE SEQUENCING}

The analysis of the $16 \mathrm{~S}$ rDNA sequence was conducted in the end of the experiment which showed no contamination in the reactor. A clean environment was provided in order to prevent any potential cross contamination during the measurements. Thereby, the purity and the stability of the inoculated culture was confirmed by the analysis.

Received I5 Augustl 202I; Received in revised form 26 August 2021; Accepted 20 September 2021;

Available online 25 September 2021;

dai: I0.4629I//CONTECHvolSiss3ppl3-ZO 


\subsection{BACTERIAL GROWTH}

The $\mathrm{OD}_{600}$ profiles in the Immobilized bioreactor over 792 hours are shown in Figure 2.

Clostridium ragsdalei was grown with $10 \%$ inoculation before being fed into the reactor and fed into the reactor after growth was terminated. Cycling was carried out in the reactor for 48 hours and the bacteria were attached to the immobilized material. The $\mathrm{OD}_{600}$ value was 0.08 when the continuous gas supply was started with a gas flow rate of $6 \mathrm{ml} / \mathrm{min}$. The cell density in the reactor decreased to 0.04 in 120 hours. At the $144^{\text {th }}$ and $312^{\text {th }}$ hours, the $\mathrm{OD}_{600}$ value increased to 0.07 and then sudden decreases were observed. The $\mathrm{OD}_{600}$ value, which reduced to 0.006 at the 360th hour, increased until the $624^{\text {th }}$ hour.

The experiments lasted 792 hours until the ethanol production stabilized. The reason of the decrease in OD values in Figure 2 is the adhesion of the bacteria on immobilized material. The fluctuation in the values can be explained by the changes between bacterial production and adhesion.

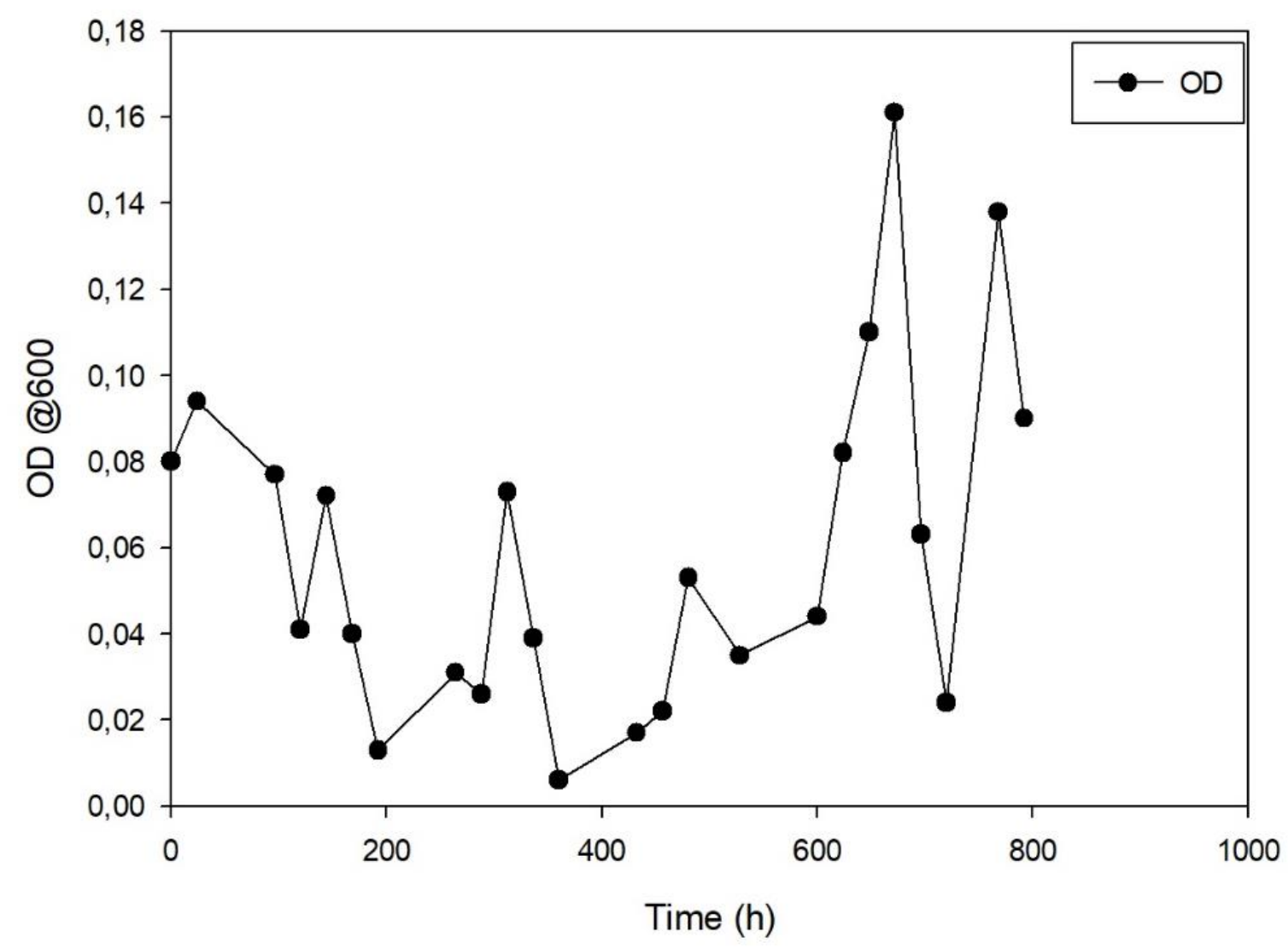

Page 17

Figure 2. Bacterial mass optical density $\left(\mathrm{OD}_{600}\right)$ profiles during continuous feed in immobilized reactor

\subsection{FERMENTATION PRODUCTS}

The Figure 4 shows the ethanol and acetic acid production performances in a continuously fed immobilized reactor. After 600 hours, $1.4 \mathrm{~g} / \mathrm{L}$ ethanol production was observed.

At the beginning of continuous fermentation, ethanol and acetic acid concentrations, which were $300.66 \mathrm{mg} / \mathrm{L}$ and $289.65 \mathrm{mg} / \mathrm{L}$ respectively, did not change significantly until the 168th hour. The ethanol and acetic acid concentrations at 168 hours were $396.67 \mathrm{mg} / \mathrm{L}$ and $196.45 \mathrm{mg} / \mathrm{L}$, respectively (Figure 3). After the $168^{\text {th }}$ hour, an increase was observed in ethanol concentration, while a decrease in acetic acid concentration was observed.

At the $624^{\text {th }}$ hour, the amount of acetic acid in the reactor increased with the sudden decrease in the ethanol value. The reason for the fluctuation encountered in the ethanol data is the production of acetic acid at high $\mathrm{pH}$ values and the production of ethanol at low $\mathrm{pH}$ values. The decrease in the amount of ethanol is explained by the conversion of the ethanol produced with the increase in $\mathrm{pH}$ to acetic acid due to the need to find a reducing equivalent (ArslanK et al.,2019).

Received I5 Augustl 202I; Received in revised form 26 August 2021; Accepted 20 September 2021;

Available online 25 September 2021;

dai: 10.46291//CDNTECHval5iss3pp|3-20 


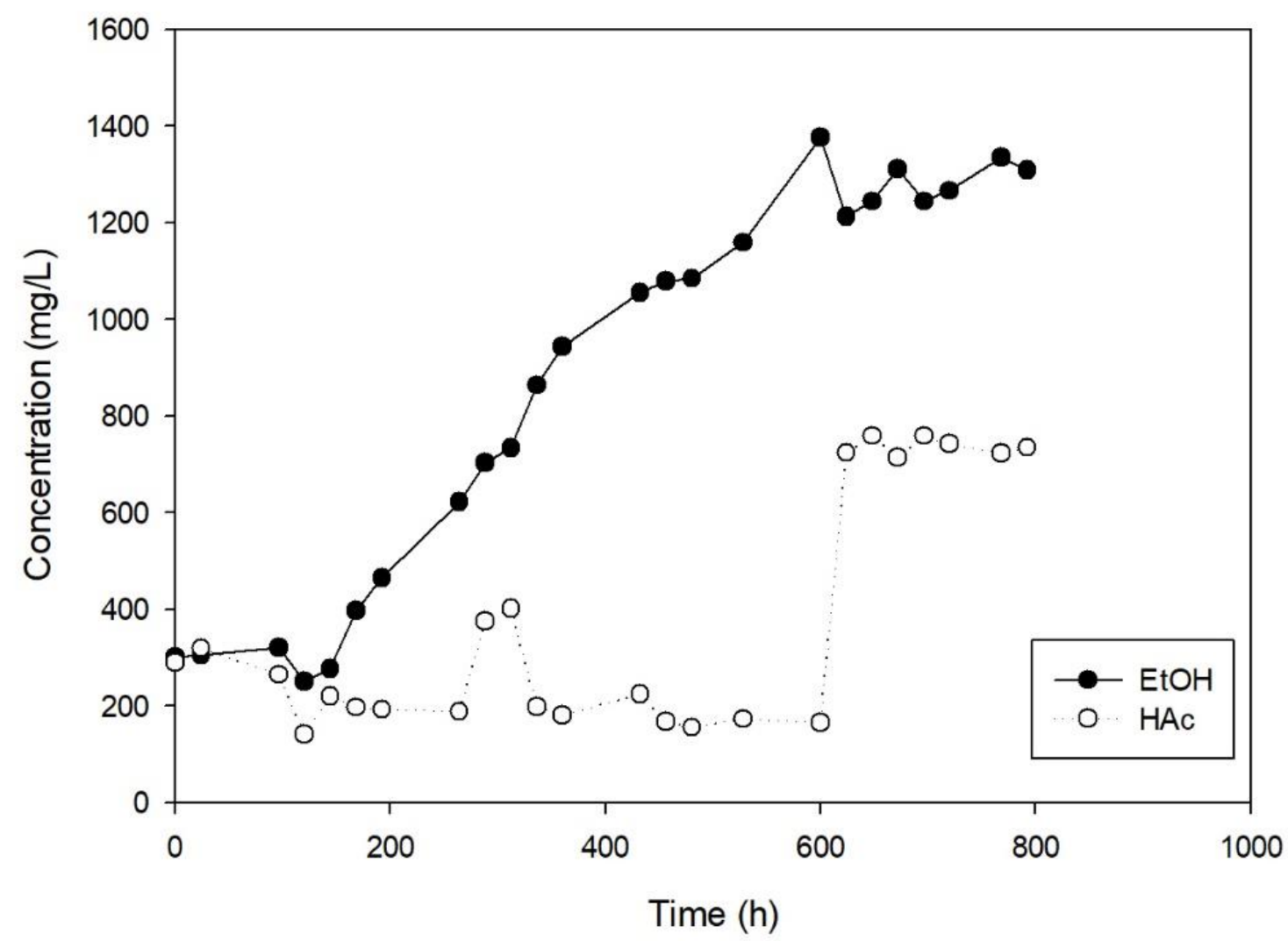

Figure 3. Ethanol and Acetic Acid production in immobilized bioreactor

When the Figure 3 is examined, it is thought that ethanol production performance can be increased by interventions for the conversion of acetic acid produced to ethanol according to the Wood-Ljungdahl pathway.

According to the metabolic pathway, ATP is released with the production of acetic acid. ATP is used in the production of ethanol. ATP balance is very important for the growth of biomass. For this reason, a very good balance between acetic acid production and ethanol production should be established and process yields should be increased.

YounesiH et al., (2006) and MohammadiM et al., (2012) used a full-mixed reactor with a volume of $20 \mathrm{~L}$ and $2 \mathrm{~L}$, respectively, in their work with a gas feed with a syngas content of $55 \% \mathrm{CO}, 20 \% \mathrm{H}_{2}, 10 \% \mathrm{CO}_{2}, 15 \%$ Ar. In both studies, a gas feed rate of $14 \mathrm{ml} / \mathrm{min}$ was used. In the reactor with a volume of $20 \mathrm{~L}$, approximately 1.7 times more ethanol was produced compared to the reactor with a volume of $2 \mathrm{~L}$. DevarapalliM et al. (2016) has reported producing $0.0034 \mathrm{~g}$ ethanol/L/h ethanol using syngas with a gas mixture of $38 \% \mathrm{CO}, 28.5 \% \mathrm{CO}_{2}, 28.5 \% \mathrm{H}_{2}$ and $5 \% \mathrm{~N}_{2}$ by volume, with Clostridium ragsdalei in a trickle bed reactor with a reactor volume of $1 \mathrm{~L}$ and a working volume of $500 \mathrm{ml}$, and $4.6 \mathrm{ml} / \mathrm{min}$ gas flow rate. In this study, $0.0023 \mathrm{~g}$ ethanol/L/h ethanol was produced by using $6 \mathrm{ml} / \mathrm{min}$ pure $\mathrm{CO}$ gas in the bioreactor where a ceramic ball with a reactor volume of $300 \mathrm{ml}$ and a working volume of $150 \mathrm{ml}$ was used as the immobilized material. This situation shows that the reactor volume is one of the parameters affecting the production performance in the production of ethanol by synthesis gas fermentation.

\section{CONCLUSIONS}

The most important end products in the Wood-Ljungdahl pathway are ethanol and acetate. Ethanol and acetate can be effectively produced from syngas containing CO. Although there are many studies in the literature on basal environment optimization with Clostridium ragsdalei, the number of reactor studies in the production of ethanol from syngas with Clostridium ragsdalei is few. The most commonly used reactor type is stirred tank reactors, and there are studies conducted with drip bed reactors. Systems in which microorganisms are immobilized are configurations that have gained importance in recent years. Gas fermentation reactors must provide high mass

Received I5 Augustl 2021; Received in revised farm 26 August 20Z1; Accepted 20 September 20ZI;

Available online 25 September 2021;

dai: I0.46291//CDNTECHval5iss3pp|3-20 
transfer capacities that meet the kinetic requirements of the microorganisms used. This study showed the potential of reducing the negative effects of air polluting gases while producing biofuels.

\section{ACKNOWLEDGMENTS}

This study was supported by TUBITAK_CAYDAG 118Y 305. Simge Sertkaya also thanks to TUBITAK_BIDEB 2214/A International Doctoral Research Fellowship Program and Chemical Engineering Laboratory (BIOENGIN group) - Faculty of Science and Advanced Scientific Research Center - La Coruña. The BIOENGIN group thanks Xunta de Galicia for financial support to Competitive Reference Research Groups (ED431C2021/55).

\section{REFERENCES}

Abubackar, H.N., Veiga, M.C., Kennes, C. 2012. Biological conversion of carbon monoxide to ethanol: Effect of $\mathrm{pH}$, gas pressure, reducing agent and yeast extract. Bioresource Technology, 114: 518-522. https://doi.org/10.1016/j.biortech.2012.03.027

Acharya, B., Dutta, A., Basu, P. 2019. Ethanol production by syngas fermentation in a continuous stirred tank bioreactor using Clostridium ljungdahlii, Biofuels, 10: 221-237. https://doi.org/10.1080/17597269.2017.1316143

AdvancedBiofuelsUSA.org, 2011. Subject: Syngas Fermentation - The Third Pathway for Cellulosic Ethanol. Report 1-6.

Arslan, K., Bayar, B., Abubackar, H.N., Veiga, M.C., Kennes, C. Solventogenesis in Clostridium aceticum producing high concentrations of ethanol from syngas, Bioresource Technology, 292: 121941. https://doi.org/10.1016/j.biortech.2019.121941

Cotter, J.L., Chinn, M.S., Grunden, A.M. 2009. Influence of Process Parameters on Growth of Clostridium Ljungdahlii and Clostridium Autoethanogenum on Synthesis Gas, Enzyme and Microbial Technology, 44 (5):281-88. DOI : 10.1016/j.enzmictec.2008.11.002

Devarapalli, M., Atiyeh, H.K., Phillips, J.R., Lewis, R.S., Huhnke, R.L. 2016. Ethanol production during semicontinuous syngas fermentation in a trickle bed reactor using Clostridium ragsdalei. Bioresource Technology, 209: 56-65. https://doi.org/10.1016/j.biortech.2016.02.086

Devarapalli, M., Lewis, R.S., Atiyeh, H.K. 2017. Continuous Ethanol Production from Synthesis Gas by Clostridium ragsdalei in a Trickle-Bed Reactor, Fermentation, 3: 23. DOI:10.3390/fermentation3020023

Dürre, P. and Eikmanns, B.J., 2015. C1-carbon sources for chemical and fuel production by microbial gas fermentation, Current Opinion in Biotechnology, 35: 63-72. https://doi.org/10.1016/j.copbio.2015.03.008

Fernández-Naveira, Á., Abubackar, H.N., Veiga, M.C., Kennes, C., 2016. Carbon monoxide bioconversion to butanol-ethanol by Clostridium carboxidivorans: kinetics and toxicity of alcohols, Applied Microbiology and Biotechnology, 100: 4231-4240. https://doi.org/10.1007/s00253-016-7389-8

Fernández-Naveira, A., Veiga, M.C., Kennes, C. 2017. Glucose bioconversion profile in the syngas-metabolizing species Clostridium carboxidivorans, Bioresource Technology, 244(1): 552-559. https://doi.org/10.1016/j.biortech.2017.07.174

Köpke, M., Mihalcea,C., Bromley,J.C., Simpson, S.D. 2011. Fermentative Production of Ethanol from Carbon $\begin{array}{lllll}\text { Monoxide, } & \text { Current } & \text { Opinion } 22(3): 325 .\end{array}$ https://doi.org/10.1016/j.copbio.2011.01.005

Kundiyana D.K, Huhnke R.L, Wilkins M.R. 2010. Syngas fermentation in a 100-L pilot scale fermentor: Design and process considerations, Journal of Bioscience and Bioengineering, 109 (5): 492-498. DOI:10.1016/j.jbiosc.2009.10.022

Kundiyana D.K, Huhnke R.L, Wilkins M.R. 2011. Effect of nutrient limitation and two-stage continuous fermentor design on productivities during Clostridium ragsdalei syngas fermentation, Bioresource Technology, 102: 6058-6064. https://doi.org/10.1016/j.biortech.2011.03.020.

Mohammadi, M., Younesi, H., Najafpour, G., Mohamed, A.R., 2012. Sustainable ethanol fermentation from synthesis gas by Clostridium ljungdahlii in a continuous stirred tank bioreactor. Journal of Chemical Technology \& Biotechnology, 87: 837-843. https://doi.org/10.1002/jctb.3712

Received I5 Augustl 2021; Received in revised form 26 August 2021; Accepted 20 September 20Z1;

Available online 25 September 2021;

dai: 10.46291//CDNTECHval5iss3pp|3-20 
Orgill, J.J., Atiyeh, H.K, Devarapalli, M., Phillips, J.R., Lewis, R.S., Huhnke, R.L., 2013. A comparison of mass transfer coefficients between trickle-bed, hollow fiber membrane and stirred tank reactors, Bioresource Technology 133: 340-346. https://doi.org/10.1016/j.biortech.2013.01.124

Phillips, J.R., Huhnke, R.L., Atiyeh, H.K., 2017. Syngas Fermentation: A Microbial Conversion Process of Gaseous Substrates to Various Products, Fermentation 28. https://doi.org/10.3390/fermentation3020028

Ramió-Pujol, S., Ganigué, R., Bañeras, L., Colprim, J., 2015. Impact of formate on the growth and productivity of Clostridium ljungdahlii PETC and Clostridium carboxidivorans P7 grown on syngas, International Microbiology, 17: 195-204. https://doi.org/10.2436/20.1501.01.222

Younesi, H., Najafpour, G., Mohamed, A.R., 2006. Liquid fuel production from synthesis gas via fermentation process in a continuous tank bioreactor (CSTBR) using Clostridium ljungdahlii, Iranian Journal of Biotechnology, 4: 45-53.

Zhu, Y. 2007. Chapter 14 - Immobilized Cell Fermentation for Production of Chemicals and Fuels, Bioprocessing for Value-Added Products from Renewable Resources New Technologies and Applications, 373-396. https://doi.org/10.1016/B978-044452114-9/50015-3 